\title{
A Novel Multi-Loop PID Controller for Photovoltaic-Grid Interface DC Energy Utilization Farm
}

\author{
A. M. Sharaf ${ }^{1}$, I. H. Altas ${ }^{2}$ and E. Ozkop ${ }^{3}$ \\ ${ }^{1}$ Energy Research Group-UTT, University of Trinidad and Tobago, Trinidad \\ e-mail: adel.sharaf@utt.edu.tt \\ ${ }^{2}$ Dept. of Electrical and Electronics Engineering, Karadeniz Technical University, Turkey \\ e-mail: ihaltas@altas.org \\ ${ }^{3}$ Dept. of Electrical and Electronics Engineering, Karadeniz Technical University, Turkey \\ e-mail: eozkop@ktu.edu.tr
}

\begin{abstract}
This paper proposes a novel control system for control of a hybrid photovoltaic PV farm utilization with alternative power source for DC type loads. A controller consisting of two different controllers is mainly used to regulate the DC-DC converter and also to control power flow from alternative power source to reduce a weighted total sum of all loop errors, to mainly track a given speed reference trajectory depicting the demand for discharge or flow and also to ensure power quality, reliability and stability. The proposed control function is digitally simulated using the MATLAB/Simulink/SimPower System software environment. The dynamic performance of the hybrid system is examined for the control system validation under normal and abnormal operating conditions.
\end{abstract}

\section{Key words}

Hybrid power system, renewable energy, modeling and simulation of power systems, photovoltaic system.

\section{Introduction}

For several decade years, fossil fuels have been extremely consumed and the reserves have been rapidly depleted much faster than new ones are being formed. The quick arise in energy demand in the industrial nation and developed countries like a China and India, which have a growing economy are increasing the requirement of more production of energy capacities [1]. Consequently, people have focused on renewable energy source search, utilization and development and thought renewable energy technologies as environmentally sustainable and convenient alternatives.

Solar is a renewable energy resource that is growing in importance because of the national and global issues of air pollution, grid reliability, dependence on foreign oil, climate change. The cost of generating electricity from the photovoltaic system has already been reduced and the cost of electricity generating of photovoltaic system may be close to the one of conventional (nonrenewable) fossil fuel energies [2]. On the other hand, the solar varies over time and is dependent on environmental conditions (temperature, irradiance, etc.). However, hybrid systems have the potential to arrange these defects.

A hybrid power system (HPS) is an electric power system that includes more than one type of energy conversion systems. There are different types of HPS, which imply different combinations of renewable energy systems (RESs), nonrenewable energy systems and storage systems (battery, flywheel, hydrogen/fuel-cell, hydropower etc.) can be used to constitute HPSs [3]. HPSs can provide the required power for the connected loads with suitable control and effective coordination between various subsystems.

The advantages of nonrenewable and renewable power conversion systems are seen in HPSs. Renewable energy sources provide autonomy from fossil fuel and also fuel prices indirectly and a sustainable power supply future. Nonrenewable energy sources are independent from environmental conditions (temperature, irradiance, wind velocity, etc.). The power utilization system safety and reliability can be strengthened to use nonrenewable energy sources when the renewable energy sources in situations of deficient environmental circumstances. To achieve a grid-linked hybrid generation system, the system should be appropriately designed with taking into consideration economic, reliability, and environmental measures subject to physical and operational constraints/strategies [4]. 
The paper is organized as follows. Section II defines the configuration and the employed models of the proposed hybrid system. Section III presents the photovoltaic-grid interface $\mathrm{dc}$ energy utilization controller structure. Section IV analyzes simulated results of two operation conditions of the proposed hybrid system. Specific conclusions are evaluated in Section V.

\section{Configuration of The Proposed Hybrid System}

The configuration of the proposed hybrid power generation system is shown in Fig. 1. The proposed system composed of Photovoltaic (PV) farms, alternative power source, $\mathrm{AC} / \mathrm{DC}$ Thyristor converter, a four quadrant PWM controlled chopper type DC-DC converter, Controllers and DC loads. In the system, DC loads are feed by the dc voltage which is obtained by the photovoltaic farm and also alternative power source.

A solar energy is more attractive than prior decade. The solar is abundant, free, environment-friendly and nonregional. A photovoltaic cell converts the solar energy into the electrical energy. To obtain the bigger electrical energy the photovoltaic cell are combined with each other by parallel and series.

During to obtain electrical energy from photovoltaic system, longitude, latitude, weather and limited daytime should be considered. Photovoltaic energy source is essentially intermittent and quite variable. It is possible that power fluctuations can be observed since photovoltaic power source is highly dependent on the weather conditions. Using photovoltaic systems for electricity generation may have more profitable in parallel with the technological advances in the near future. The different energy systems like other renewable, non-renewable and also storage energy systems can be combined with the PV farm to increase the efficiency.

In this study, the power output from PV-farm has the highest priorities to feed the load. Only if the total power from solar system is insufficient to satisfy the load demand, the certain amount of energy will be provided from the alternative power source.

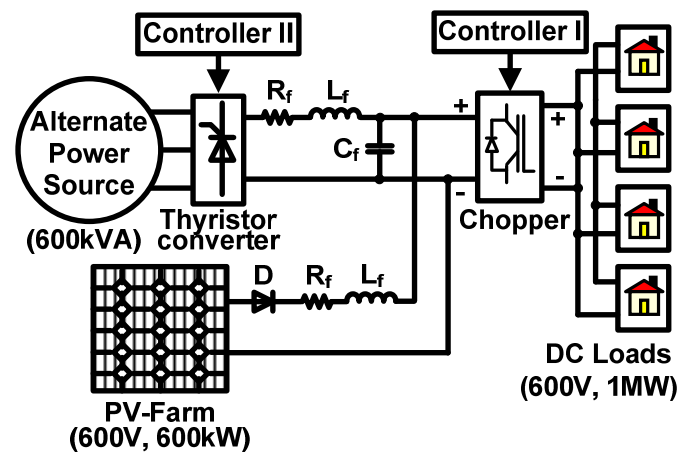

Fig. 1. Proposed grid-connected PV power generation system

\section{A. DC Motor}

DC motors are usually preferable due to their reliability, durability, low costs, voltage characteristics, positive convention coefficients between electrical and mechanical parts, sizing and design flexibility. A permanent magnet dc motor (PMDC) converts electrical power provided by a voltage source to mechanical power provided by a spinning rotor by means of magnetic coupling. The equivalent circuit of a PMDC motor is illustrated in Fig. 2. The parameters and symbols which were used in simulating the system are given in Appendix. The armature coil of the DC motor can be presented by an inductance $\left(\mathrm{L}_{\mathrm{m}}\right)$ in series with resistance $\left(\mathrm{R}_{\mathrm{m}}\right)$ in series with an induced voltage $\left(\mathrm{e}_{\mathrm{m}}\right)$ which opposes the voltage source. A differential equation for the equivalent circuit can be derived by using Kirchhoff's voltage law around the electrical loop.

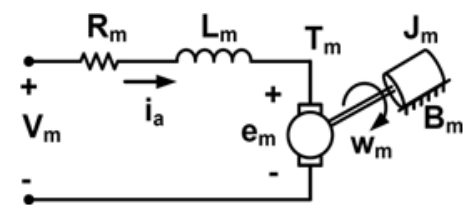

Fig 2. The equivalent circuit of a dc motor

The differential equations into state space form for the armature current and angular velocity can be written as

$$
\frac{d}{d t}\left[\begin{array}{c}
i_{a} \\
\omega_{m}
\end{array}\right]=\left[\begin{array}{cc}
-\frac{R_{m}}{L_{m}} & -\frac{K_{t}}{L_{m}} \\
\frac{K_{t}}{J} & -\frac{B}{J}
\end{array}\right]\left[\begin{array}{c}
i_{a} \\
\omega_{m}
\end{array}\right]+\left[\begin{array}{cc}
\frac{1}{L_{m}} & 0 \\
0 & -\frac{1}{J}
\end{array}\right]\left[\begin{array}{l}
V_{m} \\
T_{l}
\end{array}\right]
$$

The load torque is given by

$$
T_{L}=K_{0}+K_{1} \omega_{m}+K_{2} \omega_{m}^{2}
$$

The nonlinear inertia $\mathrm{J}$ and viscous friction $\mathrm{B}$ have the following variable non-linear forms:

$$
\begin{aligned}
& B_{m}=B_{0}+B_{1} \omega_{m}+B_{2} \omega_{m}^{2} \\
& J_{m}=J_{0}+J_{1} \omega_{m}+J_{2} \omega_{m}^{2}
\end{aligned}
$$

Where, the coefficients are chosen as given in Appendix.

\section{B. Photovoltaic Farm System}

Photovoltaic solar cells convert energy into electrical energy directly. There are two most common used models of PV cell, one diode equivalent five parameters and four parameters circuit models. The first one is more complicated than the second one [5]. In this application, four parameters, which are functions of solar irradiance, load current and temperature, circuit model is realized. The arranged equivalent circuit model is shown in Fig. 3 [6-7]. 


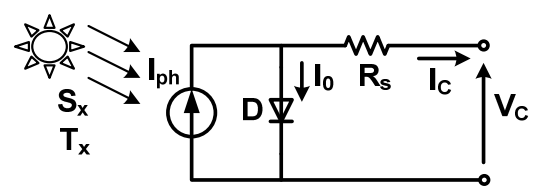

Fig. 3. One diode equivalent four parameters PV model

The PV array equivalent circuit was modeled as a single block called PVA Model. This model simulates the characteristic of the solar panel with the equation given in Appendix.

\section{Alternative Power Source}

The alternative power source is used to help support the system when the PV farm power is not enough to provide energy through the DC loads. If the PV farm system gives a required the loads power, the alternative power source will be disconnected from the line. In this way, the electrical energy is efficiently obtained from the renewable energy source and the AC power source when the PV Farm power is not sufficient.

\section{Controller Structure}

There are two type controllers in the proposed system. One of the controllers named as Controller-II is used to arrange the alternative power source output connected to the PV farm power system. Another controller named as Controller-I controls the DC loads power flow.

The Controller-II is to adjust the alternative power source voltage and also to change the chopper input dc voltage shown in Fig. 4. The controller consists of two different tri-loop controllers. There are Tri-loop A and Tri-loop B controllers.

The photovoltaic current, photovoltaic voltage and photovoltaic power constitute the Tri-loop A controller inputs. Every input error is obtained by taking the difference between the real and delayed real input values. The photovoltaic voltage error, the photovoltaic current error and the photovoltaic power error are multiplied by the related weight factors $\left(\gamma_{\mathrm{I}}, \gamma_{\mathrm{v}}\right.$ and $\left.\gamma_{\mathrm{p}}\right)$ and the output summations is a total Tri-loop A error. The tri-loop error is multiplied by a weight factor $\left(\mathrm{K}_{1}\right)$.

The thyristor rectifier output current, the thyristor rectifier output voltage and the thyristor rectifier output power constitute the Tri-loop B controller inputs. Every input error is obtained by taking the difference between the real and delayed real input values, except for the rectifier voltage. The input error is obtained by taking the difference between the real and reference voltages. The rectifier voltage error, the rectifier current error and power error are multiplied by the related weight factors $\left(\gamma_{\mathrm{vR}}, \gamma_{\mathrm{IR}}\right.$ and $\left.\gamma_{\mathrm{pR}}\right)$ and the output summations is a total Tri-loop B error. The tri-loop error is multiplied by a weight factor $\left(\mathrm{K}_{2}\right)$. The summation of the tri-loop errors (Tri-loop A, Tri-loop B) forms the input of conventional
PID controller. The PID controller output is limited between -1 and 1 . The limited value goes through the trigonometric block $\left(\cos ^{-1}\right)$. The trigonometric block output determines the thyristor rectifier trigger angle. The thyristor rectifier output dc power value varies with depending on the trigger angle.

The Controller-I consists of three different loops shown in Fig. 5. There are speed loop, current loop and current $\&$ speed loop. In current and speed loop, the real and reference values are compared to obtain current and speed error. In current \& speed loop, real current and speed values are multiplied by each other and the current $\&$ speed error is obtained by taking the difference between the output value and the delayed output value. The chopper speed error, the chopper current error and the chopper current\&speed error are multiplied by the related weight factors $\left(\gamma_{\omega}, \gamma_{\mathrm{m}}\right.$ and $\left.\gamma_{\mathrm{I}}\right)$ and the output summations is a total tri-loop error $\left(\mathrm{e}_{\mathrm{t}}\right)$.

The total tri-loop error forms the input of the conventional PID controller. The controller output determines the switches states.

In the all system, the photovoltaic array is directly connected to the chopper input. It is possible that power fluctuations can be seen since PV-farm power source is highly dependent on the weather conditions. The Controller-II regulates the alternative power source depending on the system load requirement. If the photovoltaic module system does not supply the necessary load power, the Controller-II adjusts the alternative power source to produce the required power by the load. Otherwise, the alternative power source is passive by using the Controller-II. In this way, a flexible power management is realized in the hybrid power system.

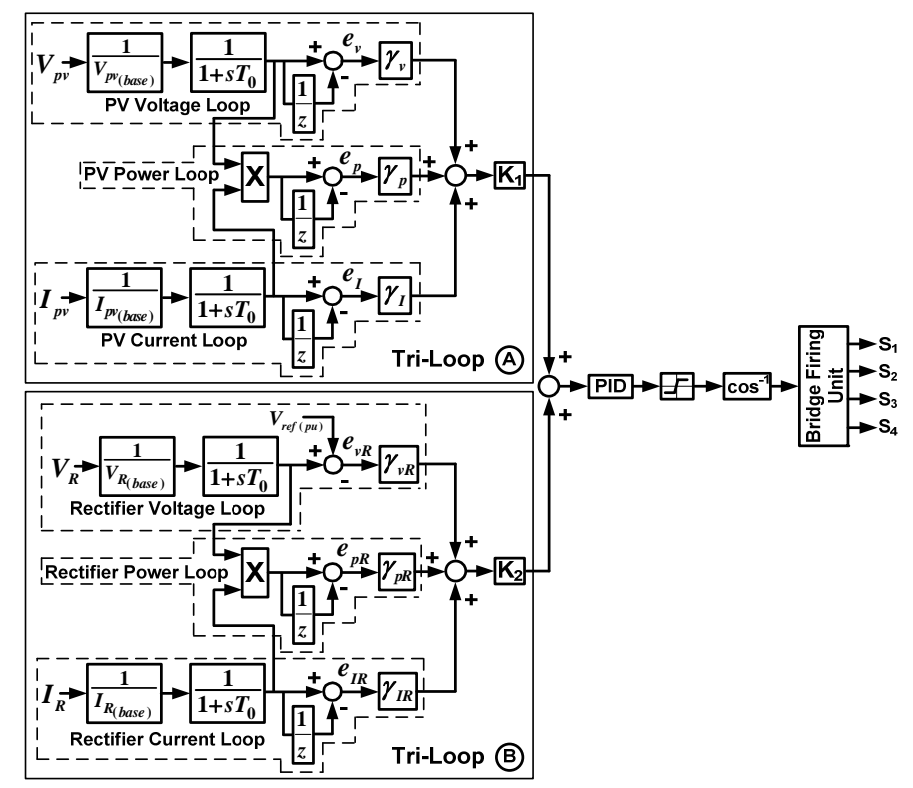

Fig. 4. Six-loop dynamic error driven PID controller (Controller-II) 


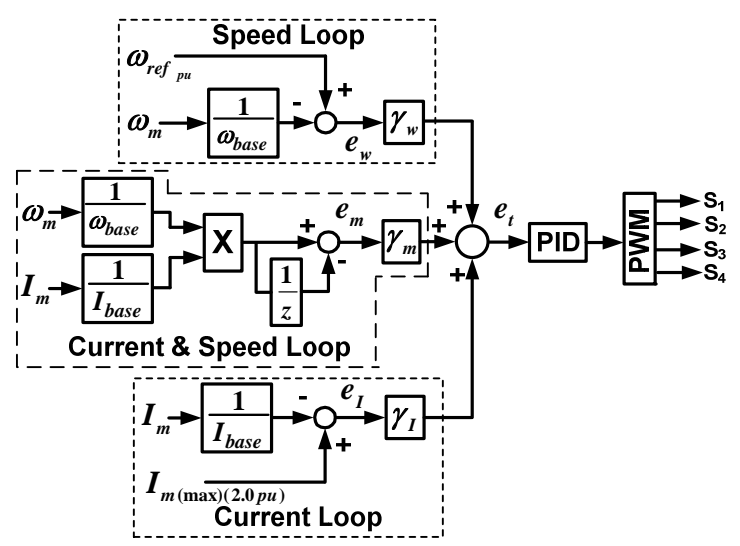

Fig. 5. Tri-loop dynamic error driven PID controller (Controller-I)

When the available PV farm power is insufficient to supply the load, the alternative power source delivers additional electricity. But if the PV farm is strong enough to completely supply the load, the alternative power is inactive. The purposed system is digitally simulated by using the Matlab/Simulink/SimPower Software and is shown in Fig. 18.

\section{Simulation Results}

The hybrid renewable energy system is tested with two different conditions. Firstly, one of the variable references applied through the DC loads in time increases linearly and reaches the $200 \mathrm{rad} / \mathrm{s}$ at the end of the first $500 \mathrm{~ms}$, and then the reference speed remains speed constant during 1 second. At $1.5^{\text {th }}$ second, the reference speed decreases with same slope as at the first $500 \mathrm{~ms}$. After 2 second, the motor changes the direction and DC loads increase its speed through the reverse direction. At $2.5^{\text {th }}$ second, the reference speed reaches the $-200 \mathrm{rad} / \mathrm{s}$ and remains this speed at the end of $3.5^{\text {th }}$ second and then the reference speed decreases and becomes zero at $4^{\text {th }}$ second. This reference speed waveform is named as Type I in this study. Another variable reference named as Type II has same waveform with maximum and minimum 100 $\mathrm{rad} / \mathrm{s}$ and $-100 \mathrm{rad} / \mathrm{s}$, respectively. In all references, the system responses have been observed.

The DC loads need in Type I more power than Type II, because the system reference speed in Type I is bigger than the speed in Type II. So the DC loads consume more power in Type I condition than in Type II condition. When the available PV farm power is insufficient to supply the load, the alternative power source delivers additional electricity. But if the PV farm is strong enough to completely supply the load, the alternative power source is in active. The DC loads total current consumption in Type I is bigger than it in Type II shown in Fig. 7 and Fig. 13, respectively. When the available PV farm power is insufficient to supply the load like in Type I, the alternative power source delivers additional electricity as shown in, Photovoltaic output voltage and current and thyristor converter output current waveform in Fig. 9, Fig. 10, and Fig. 11, respectively.

\section{Conclusion}

The paper presents a digital model and validation study of a green renewable PV-powered Farm with DC type motorized loads using novel controllers. In the hybrid power generation system, different power systems are connected the systems together and complement one another to serve the load to fulfill certain economic, environmental, and reliability criteria.

The control strategy is based on source-load matching that is fully suitable for hybrid photovoltaic PV farm with alternative interface connection to the local electric grid. The dynamic Controller-I and Controller-II schemes are mainly used to regulate the DC-DC converter and also to control power flow from alternative power source to reduce a weighted total sum of all loop errors and to mainly track a given speed reference trajectory depicting the demand for discharge or flow.

The real inherent nonlinearity of motor and mechanical load inertia, viscous friction as well as any load torque excursions are all modeled as nonlinear functions of the motor speed. The proposed novel control scheme has been validated for both effective and good dynamical speed reference trajectory tracking with enhanced power/energy utilization.

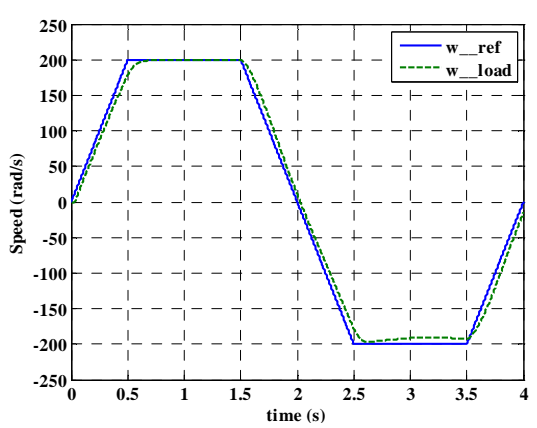

Fig. 6. Speed waveform (Type I)

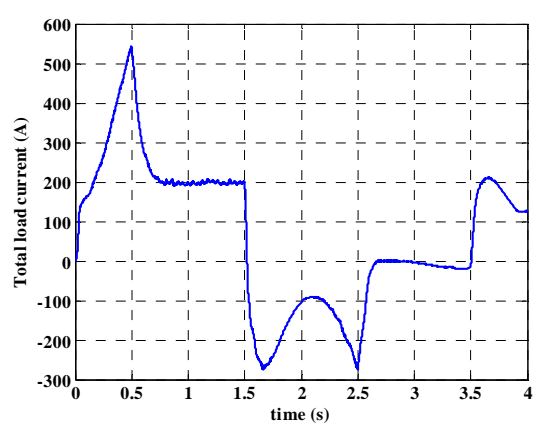

Fig. 7. Total load current waveform (Type I)

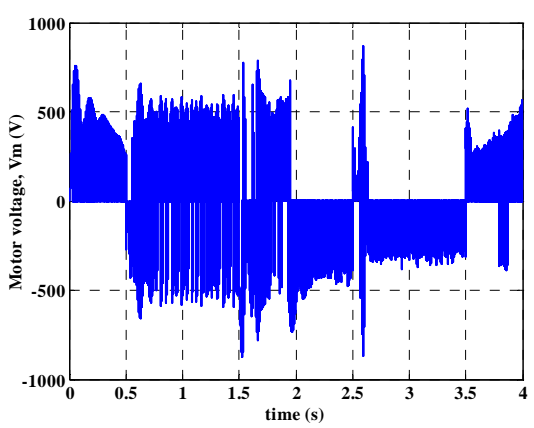

Fig. 8. Motor voltage waveform (Type I) 


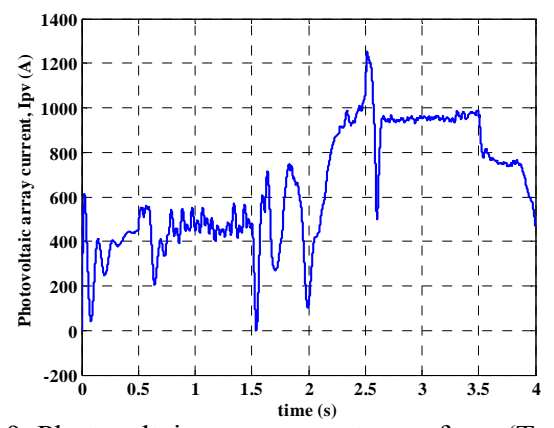

Fig. 9. Photovoltaic array current waveform (Type I)

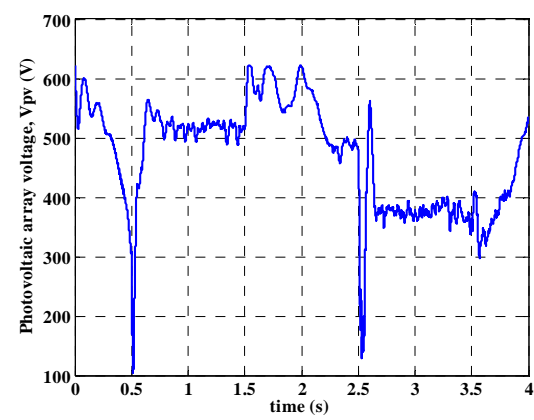

Fig. 10. Photovoltaic array voltage waveform (Type I)

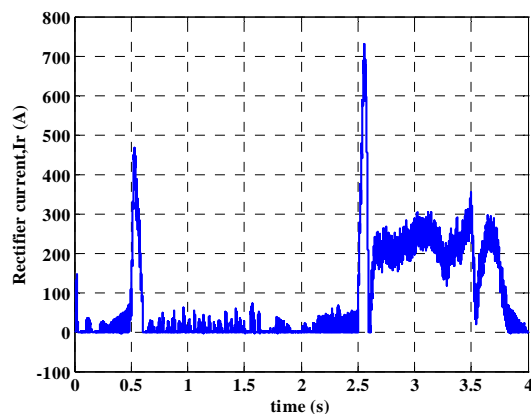

Fig. 11. Rectifier current waveform (Type I)

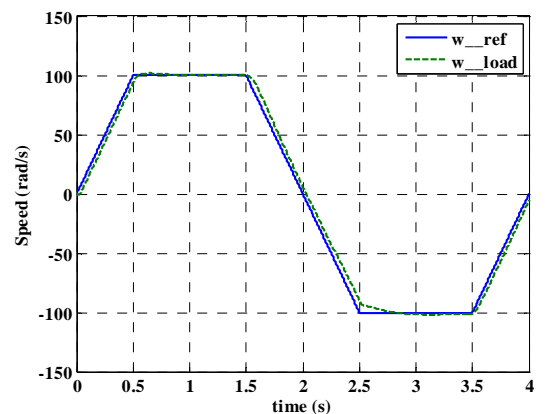

Fig. 12. Speed waveform (Type II)

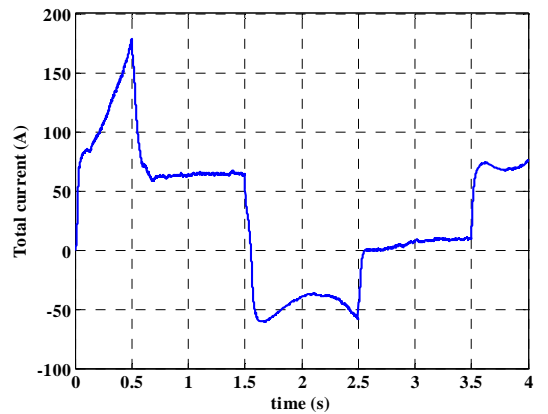

Fig. 13. Total load current waveform (Type II)

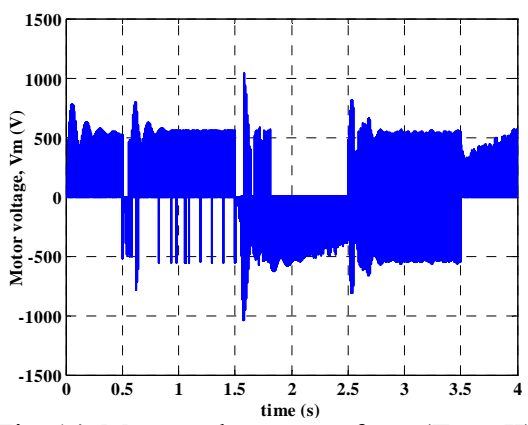

Fig. 14. Motor voltage waveform (Type II)

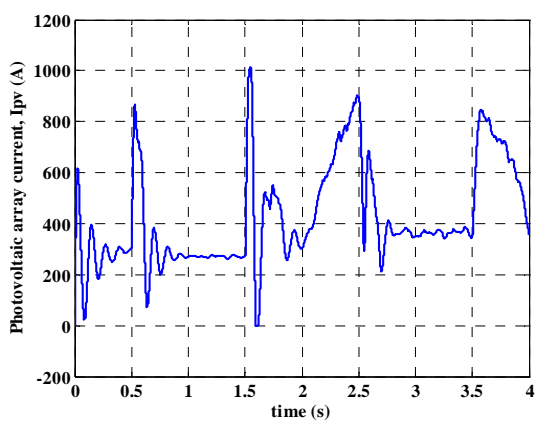

Fig. 15. Photovoltaic array current waveform (Type II)

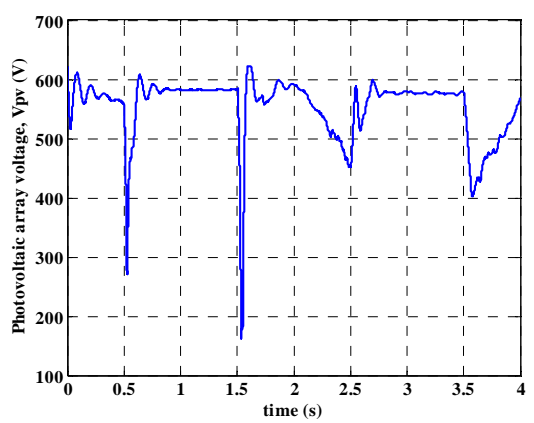

Fig. 16. Photovoltaic array voltage waveform (Type II)

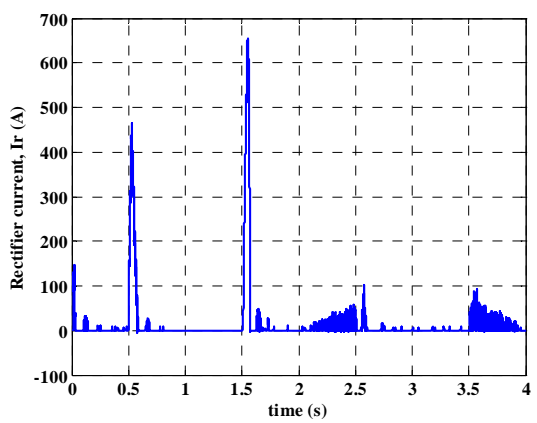

Fig. 17. Rectifier current waveform (Type II)

\section{Appendix}

PV Array modeling equations:

$$
\begin{aligned}
& V_{p v}=V_{c} * C_{T V} * C_{T I} * N_{s} \\
& V_{c}=\frac{A K T_{c}}{e}\left(\frac{I_{p h}+I_{0}-I_{c}}{I_{0}}\right)-R_{s} I_{c} \\
& I_{c}=I_{p v} / N_{p}, I_{p v}=C_{T I} * C_{S I} * I_{s c} \\
& C_{T V}=1+\beta_{T}\left(T_{c}-T_{x}\right), C_{S V}=1+\beta_{T} \alpha_{S}\left(S_{x}-S_{c}\right) \\
& C_{S I}=1+\frac{1}{S_{c}}\left(S_{x}-S_{c}\right) C_{T I}=1+\frac{\gamma_{T}}{S_{c}}\left(T_{x}-T_{c}\right)
\end{aligned}
$$




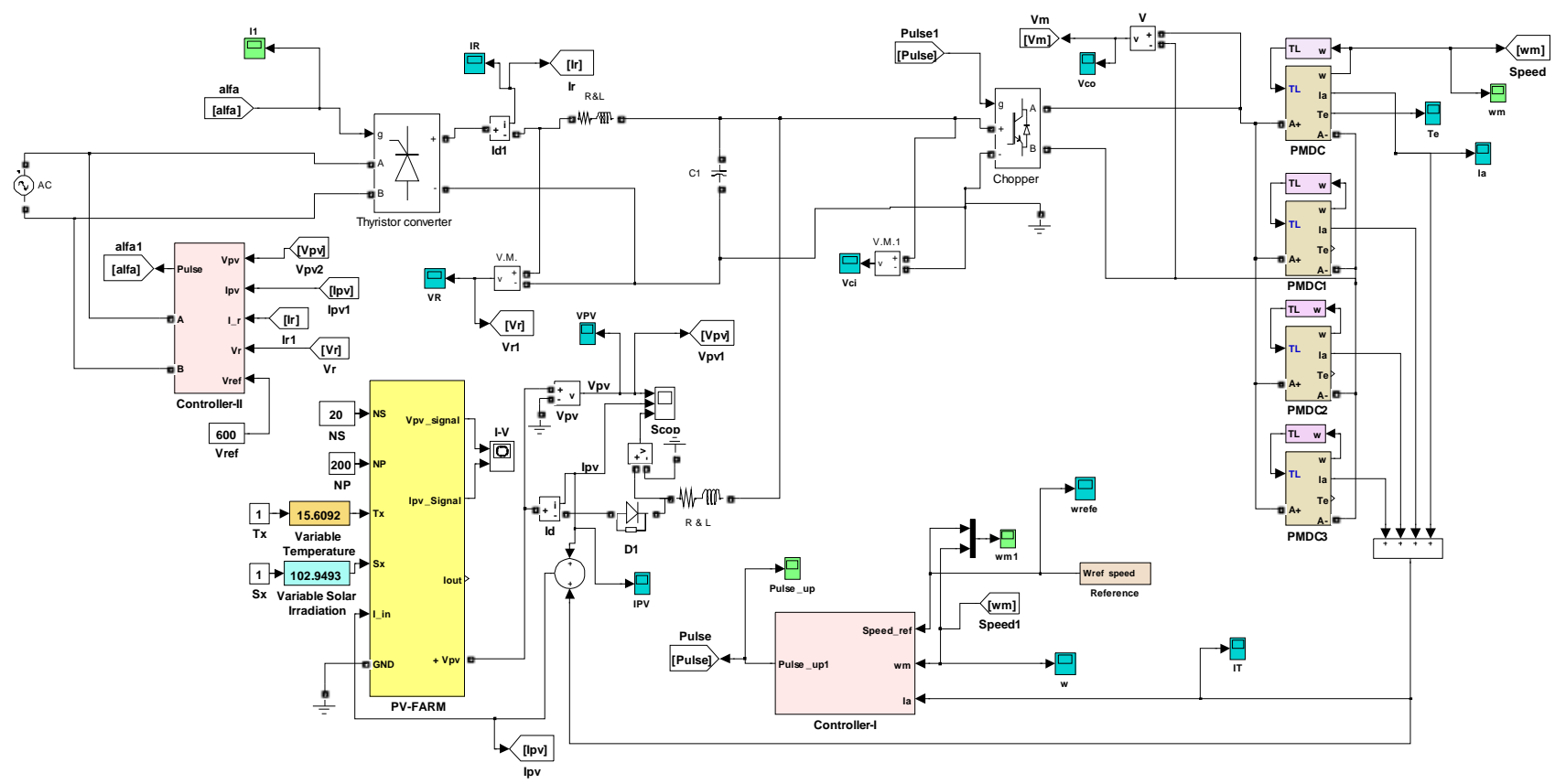

Fig. 18. The proposed hybrid renewable energy system Simulink block diagram

\begin{tabular}{|c|c|c|}
\hline Voltage source & $V_{m}$ & $600 \mathrm{~V}$ \\
\hline Inductance & $\mathrm{L}_{\mathrm{m}}$ & $3 \mathrm{mH}$ \\
\hline Resistance & $\mathrm{R}_{\mathrm{m}}$ & $1.19 \Omega$ \\
\hline Induced voltage & $\mathrm{e}_{\mathrm{m}}$ & $\mathrm{V}$ \\
\hline Actual rated speed & $W_{\text {a-rated }}$ & $500 \mathrm{rad} / \mathrm{s}$ \\
\hline Back emf constant & $\mathrm{K}_{\mathrm{e}}$ & $0.2 \mathrm{~V} . \mathrm{s} / \mathrm{rad}$ \\
\hline Electromagnetic torque & $\mathrm{T}_{\mathrm{e}}$ & $\mathrm{Nm}$ \\
\hline Motor speed weighting factor & $\gamma_{\mathrm{w}}$ & 1 \\
\hline Motor current weighting factor & $\gamma_{I}$ & 0.001 \\
\hline $\begin{array}{l}\text { Motor current\&speed weighting } \\
\text { factor }\end{array}$ & $\gamma_{\mathrm{m}}$ & 0.1 \\
\hline \multicolumn{3}{|c|}{$\begin{array}{c}\text { Input filters } \\
\mathrm{R}_{\mathrm{f}}=0.05 \Omega, \mathrm{L}_{\mathrm{f}}=0.05 \mathrm{H}, \mathrm{C}_{\mathrm{f}}=20 * 10^{-6} \mathrm{~F}\end{array}$} \\
\hline \multicolumn{3}{|c|}{$\begin{array}{c}\text { Load torque constants } \\
\mathrm{K}_{0}=0.9, \mathrm{~K}_{1}=3.9^{*} 10^{-3}, \mathrm{~K}_{2}=66^{*} 10^{-6}\end{array}$} \\
\hline \multicolumn{3}{|c|}{$\begin{array}{c}\text { Viscous friction constants } \\
\mathrm{B}_{0}=5.7 * 10^{-3}, \mathrm{~B}_{1}=25^{*} 10^{-6}, \mathrm{~B}_{2}=0.423 * 10^{-6}\end{array}$} \\
\hline \multicolumn{3}{|c|}{$\begin{array}{c}\text { Rotor moment of inertia constants } \\
\mathrm{J}_{0}=14.44 * 10^{-3}, \mathrm{~J}_{1}=62.6^{*} 10^{-6}, \mathrm{~J}_{2}=1.06 * 10^{-6}\end{array}$} \\
\hline
\end{tabular}

$\beta_{T}$ : Temperature coefficient $1(1 / \mathrm{K})$

$\mathrm{T}_{\mathrm{x}}$ : Ambient temperature $(\mathrm{K})$

$\gamma_{T}:$ Temperature coefficient $2(1 / \mathrm{K})$

$\alpha_{S}:$ Irradiation coefficient

$\mathrm{S}_{\mathrm{x}}$ : Ambient irradiation (\%)

$\mathrm{S}_{\mathrm{c}}$ : Photovoltaic cell operating irradiation (\%)

\section{References}

[1] "Deciding the Future: Energy Policy Scenarios to 2050", World Energy Council, September, 2007.

[2] "Renewables 2007 Global Status Report", REN21, 2008 Deutsche Gesellschaft für Techniche Zusammenarbeit (GTZ) GmbH.

[3] C. Wang, L. Wang, L. Shi and Y. Ni, "A Survey on Wind Power Technologies in Power Systems", IEEE Power Engineering Society General Meeting 2007, Tampa, FL, USA, 24-28 June 2007.

[4] L. Wang and C. Singh, "PSO-Based Multidisciplinary Design of A Hybrid Power Generation System with Statistical Models of Wind Speed and Solar Insolation", International Power Electronics, Drives and Energy Systems, 2006, PEDES'06, 12-15 Dec. 2006.

$\mathrm{V}_{\mathrm{pv}}$ : Photovoltaic array output voltage (V)

$\mathrm{V}_{\mathrm{c}}$ : Cell output voltage $(\mathrm{V})$

$\mathrm{C}_{\mathrm{TV}}$ : Temperature-voltage coefficient

$\mathrm{C}_{\mathrm{SV}}$ : Irradiation-voltage coefficient

$\mathrm{N}_{\mathrm{s}}$ : Number of solar cells connected in series

A: Diode quality factor (6.2)

$\mathrm{K}$ : Boltzman' constant $\left(1.38 * 10^{-23} \mathrm{~J} / \mathrm{K}\right)$

$\mathrm{T}_{\mathrm{c}}$ : Photovoltaic cell operating temperature $(\mathrm{K})$

$\mathrm{I}_{\mathrm{ph}}$ : Photocurrent, function of irradiation level and junction temperature (A)

$\mathrm{I}_{0}$ : Reverse saturation current of the diode D $(0.01 \mathrm{~A})$

$\mathrm{I}_{\mathrm{c}}$ : Cell output currrent (A)

e: Charge on an electron $\left(1.60 * 10^{-19} \mathrm{C}\right)$

$\mathrm{R}_{\mathrm{s}}$ : Series resistance of the photovoltaic cell $(0.002 \Omega)$

$\mathrm{I}_{\mathrm{pv}}$ : Photovoltaic array current (A)

$\mathrm{N}_{\mathrm{p}}$ : Number of solar cells connected in parallel

$\mathrm{C}_{\mathrm{SI}}$ : Irradiation-current coefficient

$\mathrm{C}_{\mathrm{TI}}$ : Temperature-current coefficient

$\mathrm{I}_{\mathrm{sc}}$ : Cell short circuit currrent (A)

[5] A.A. Ghoneim, "Design optimization of photovoltaic powered water pumping systems", Energy Conversion \& Management, pp. 1449-1463, 2006.

[6] I.H. Altas and A.M. Sharaf, "A novel GUI modeled fuzzy logic controller for a solar powered energy utilization scheme", The 13th International Conference on Emerging Nuclear Energy Systems (ICENES2007), June 3-8, 2007, Istanbul, Turkey.

[7] I.H. Altas and A.M. Sharaf, "A photovoltaic array simulation model for Matlab-Simulink GUI environment", International Conference on Clean Electrical Power, ICCEP'07, May 21-23, 2007, Capri, Italy. 